\title{
Review of Reshaping the University: Responsibility, Indigenous Epistemes, and the Logic of the Gift
}

LYNDA LANGE

Department of Philosophy, University of Toronto, Toronto, Ontario, Canada

Reshaping the University: Responsibility, Indigenous Epistemes, and the Logic of the Gift.

By Rauna Kuokkanen

Vancouver, University of British Columbia Press, 2007. ISBN \# 978-0-7748-1356-3

According to Rauna Kuokkanen, "indigenous people who come to the university face many challenges and difficulties, including benevolent ignorance, misconceptions about their cultures, individual and institutional discrimination, and systemic marginalization" (p. 49). Rejecting "culture" as a term for their "difference," as not only too vague, but also limited in the sense that multicultural appreciations of culture can too easily leave colonial structures unaddressed, Kuokkanen uses the notion of an "episteme" to make her arguments concerning the depth of exclusion and silencing that indigenous students and intellectuals face in contemporary universities. The notion of an episteme may in large part be understood by what it is not. It is not an epistemology in the sense in which Western philosophers have different epistemological views concerning how we can claim to know that a proposition is true. These differing ideas are all within the same philosophical tradition, and hence, all within the same episteme. An episteme is a primary and comprehensive worldview with a particular ontology that tells those within it what exists or is "real," and hence what can be considered "true" or "false," as opposed to "meaningless." A fundamental claim of the author is that there is a distinctive indigenous episteme that has been marginalized or even invisible within Western universities. This cannot be corrected by dialogue or "inclusion" that remains uncritically within the same Western episteme, but requires a fundamental shift in attitude. Kuokkanen shares with numerous other "critical epistemologists" the view that approaches to knowledge, and knowledge production, are ultimately inextricable from ethical considerations. This work sets out an important nonassimilationist analysis of the possibilities for indigenous intellectual life in the university, and for the university as a whole. However, there is occasional slippage 
in this work between "episteme" and "epistemology" and "philosophy," attesting to the difficulty of writing about these concerns.

As Kuokkanen writes, the world's idea of the university was shaped in the 19th Century to be Enlightenment: modern, liberal, and also colonial. This general idea is indisputable, but as Edward Said wrote in his introduction to Orientalism (1979) concerning his claims that "knowledge is political," this is one of those ideas that can receive wide assent and at the same time not be considered to be of much importance. It is therefore important that Kuokkanen, like Said, goes into considerable depth to explain what has occurred, and continues to occur, in the university so characterized, regarding indigenous intellectual life. She draws on a great range of theoretical literature in making her analysis, using deconstruction (especially Derrida and Spivak), critical theory, and postcolonial theory. In addition, her mix of resources differs from many others by including her extensive and informative use of contemporary indigenous theoretical works in education, such as those by Patricia Monture-Angus, Devon Mihesuah, and Angela C. Wilson.

Kuokkanen gives credit to those who have struggled to make universities more open and acknowledges that this is what has made work like hers possible. In the last many decades, universities have been pressured to be inclusive of previously marginalized groups. Responses have ranged from more inclusive admission policies, to affirmative action approaches, to creating more diverse faculty that may be scholarly role models to a diverse student body, to the creation of new programmes (e.g. women's studies, sexual diversity studies, and many "area" studies). Most of us are also familiar with the generally well intended efforts of many university people to make scholarly events such as conferences, as well as committees and governing bodies more representative of the diversity of students, or the diversity of the society of which the university is a part. Even the more conservative among academic people now seem to accept some version of the "politics of recognition," as well as the inevitability of inclusiveness, that is, of "letting in" those previously excluded.

Kuokkanen argues that these developments, though they can be important steps, are nonetheless limited by the very notion of "including" people of diverse backgrounds in an "episteme" that is not, in spite of its pretensions or aspirations, really "objective" or "universal," but historically specific to the dominant and colonizing strain of modern Western thinking. This thinking is modern in the sense of considering itself "free," that is, against any authority of tradition (or at least any non-European tradition). It is an "exchange" economy in the sense of requiring, or at least expecting, the exchange of value for value. If I produce value, whether widgets or writings, I ordinarily expect a return of payment or, in the case of ideas, at least recognition that these ideas, or designs for widgets, are mine. Kuokkanen's book reminds us how closely these exchange expectations are related both to hegemonic standards of rationality (especially "rational self-interest" in economic terms) and to our ideals of individual autonomy. If I give and take value for value, I am under no obligation to others or they to me; I am independent. Even justice seems to follow this model-I "have" my rights, separately from others, and there are rules concerning what can be done with them. This exchange economy no doubt has seemed to many to be only sensible, but it is this mentality of exchange, ownership, and competition, that has made it possible for the university and the "value" it 
produces to be made to conform more and more to neo-liberal monetarist expectations, a development that Kuokkanen, along with many other commentators, particularly laments.

This work takes a basic position that the marginalization of indigenous peoples is not (only) a question of racism or ethnic minority rights, but it is a marginalization of peoples with rights to self-determination. In the academy, their episteme (to be explained more fully below) is generally not only ignored, but also not even recognized as such, that is, as a worldview that is another complete discourse. The university assumes that its Western, modern episteme is not only the best one for the pursuit of knowledge, but really the only one.

Writing from an indigenous perspective (she is herself Sami), Kuokkanen exposes the limitations and specificity of these expectations by setting out a profoundly different episteme, which she terms "the logic of the gift." Derrida has famously argued that modernity, including philosophy itself, is characterized by constant efforts to externalize the "other" in various ways, in vain attempts to get at coherent self-identity and tell a single coherent story about itself. For example, all territories have (and have always had) diverse populations, but the development of the modern nation-state involved repressing differences by subsuming them under a unified narrative about the "nation." But the "other" is "always already" (that ubiquitous phrase in deconstruction) in society, in thought and language, and even in what one may take to be one's "self." It is the frustrated effort to effect this externalization that is the source of many different senses of modern violence (e.g. physical, social, intellectual, colonial). Europeans did intellectual (along with other) violence to indigenous peoples by claiming that their beliefs were/are primitive, irrational, or even incomprehensible. As the author states, "the construction of the colonial subject depends on the indigenous 'other,' who can only be represented by that subject” (p. 83). Derrida, partly inspired by Levinas, maintains that all ethics are exemplified by the nature of our relation to the "other," and proffers the ethic of hospitality and "the gift." We should welcome the "other" and give to them, without anticipating a return of some kind in exchange. In respecting the dignity and validity of the "other," we must also respect the concrete distinctiveness of their contexts from their point of view, accepting them without demanding to be able to comprehend them by means of predetermined categories of our own. Kuokkanen makes use of these ideas, but also questions them, adding her own and others' understanding of indigenous epistemes, to put forward her own "logic of the gift."

In this alternative way of thinking, which is held to be characteristic of indigenous societies, one routinely gives or shares with others. One gives to individuals and the community, of course, but in indigenous epistemes one also gives to the natural world that sustains human life, or to aspects or places in it. One does this without an expectation of something in direct exchange, or even of equal value. If I give something to you, you will later give something else to a third party. It is an economy of circulation that implicitly acknowledges both human interdependence and human dependence on the non-human world. In indigenous gift logic it is important that I may also extend intangibles such as respect, gratitude, and prayers, and these also circulate and contribute to the bonds of interdependence. Kuokkanen is of course mindful that indigenous peoples are not homogeneous, but she also maintains that they share certain values driven by their age-old intimate relationship 
with the natural world and their ethic of relationship, reciprocation, reverence, and responsibility to both human and non-human beings.

Kuokkanen particularly criticizes the "sanctioned ignorance" in the academy concerning indigenous epistemes and issues. She notes, I think correctly, that academics generally have the privilege of simply not knowing, without any embarrassment, about indigenous epistemes and issues, a stance that I think is also often found with regard to any area of study that proposes social change and lessening of oppression of a non-hegemonic group. Foucauldean uses of the notion of an episteme often stress incommensurability, but Kuokkanen is serious about the need for non-indigenous learning about indigenous epistemes, and seems to reject the notion that epistemes are necessarily unintelligible to each other, even as she discusses the problem of translation.

For indigenous epistemes to cease to be marginalized and silenced, Kuokkanen argues that this episteme must first be recognized as such and received as a gift by others in the academy. This is in large part because our natural world is in peril and we need a new ethic of responsibility toward it, but also to move the university away from the type of hierarchy that has its roots in colonialism, such as the privileging of certain cultures and disciplines. Philosophical readers may wonder about an apparent claim to "universality" in the context of deconstructionist critique, but Kuokkanen's argument is not about shifting from one episteme to another, but about listening and learning across epistemes. Following the logic of the gift, this practice must be a learning process that involves the epistemic "gift logic" virtues of respect, responsibility, and reciprocity. This should be an ongoing practice, rather than a study that could ever be definitively concluded. This approach recommends engaging the process and not trying to settle in advance questions of universality, incommensurability, and so on.

None of this can be really persuasive unless readers can fully absorb the reality that, despite colonization, indigenous peoples and their epistemes continue to exist and develop. We have no way of knowing how indigenous people may have developed, intellectually or otherwise, without the extreme measures taken to try to extinguish them as peoples. Although there can be no return to authenticity uncontaminated by the experience of colonialism, nonetheless, as Kuokkanen puts it, their epistemes, as they are now, are sui generis yet contemporary. It is fundamental to Kuokkanen's non-assimilationist approach that indigenous epistemes have their own independent history, going back as far as we may be able to go, but at the same time have continued to develop and change, as all human epistemes do, into the present. They should therefore be acknowledged as contemporary and not, as it were, frozen in thought as "ancient."

It is also useful for non-indigenous readers to be reminded that indigenous thinkers sometimes disagree with each other. Given her position, it may be surprising that Kuokkanen shares a critique with aboriginal political theorist Dale Turner of aboriginal thinker Taiaiake Alfred. Alfred's call for a return to indigenous culture as a necessity for decolonization, however reasoned, strikes them both as a kind of unfeasible cultural fundamentalism.

Kuokkenen stresses the need for very radical change concomitant with the realization of the limitations of the exchange ethic and the learning of the gift ethic, along with acknowledgment that there are diverse epistemes. At times she offers a 
kind of immanent critique of the university in saying that its silencing and exclusion of "other" epistemes contradicts its own objective of free and open-ended pursuit of knowledge. In my view, this idealization of the university suffers from a conflation of the university and the world not unfamiliar in radical critics of the university wherein the university is treated as a complete world that should fulfill all things. However, this approach neglects the really sticky question of the university's role as an institution that accords recognized credentials. I think (and the author may well agree) that it is societies at large that need this freedom and open-endedness, before the university can be transformed.

Many are disappointed by the narrowness and/or corporatization of universities, so it is important that the author affirms that we are in fact able to understand epistemes other than the one most basic to us at a particular time. In attempting to do this as a reader, in relation to the themes of this work, I wondered if the logic of the gift, as a powerful episteme, might have its own potential for exclusion. I am sure that Kuokkenen is right that land-based communities have a greater sense of interdependence and responsibility to each other and to the natural world than mobile modern "individuals," but surely they also have a sense of who is a stranger. On the other hand, there is a sense in which academics, even in present circumstances, do not completely fail to practice the logic of the gift. I think many academics practice "the gift" (not calling it that), with recognition, reciprocity, and responsiveness, at conferences, in discussions, and conversation. The limitation here is that this occurs within self-chosen circles. Those unlucky enough not to be admitted to a circle that is relevant for the development of their work (and this can happen for a multitude of reasons) can have a severe sense of marginalization even though they do not have a different episteme. The logic of the gift may not spare us the need to decide who is included.

These thoughts are matters for ongoing discussion. What is most important now is the acknowledgement that "there is an alternative vision of the human: those who have stayed in place for more than thirty thousand years" (p. 155). Whether or not the university at the institutional level, or Western societies in general, can learn how to "enlarge the circle" is an important question for the future of all of us. 